\title{
Contribuições da bioética para a saúde pública
}

Para uma adequada compreensão da bioética contemporânea e de suas relações com a saúde pública é apropriado um retorno às suas origens. Embora formalmente reconhecida sua origem no trabalho de Potter e no de Hellegers, é razoável situar o surgimento das reflexões que viriam a se conformar como bioética no âmbito das preocupações com as repercussões das pesquisas envolvendo seres humanos e em eventos mais associados à clínica, como o episódio da criação do Life or Death Committee, em Seattle, Estados Unidos, relacionado com a escolha dos que seriam atendidos pelo programa de diálise renal. Em ambos os casos a relação direta com a saúde pública já é evidente. O foco dado aos aspectos clínicos nas análises habituais desses episódios pode ser apenas um reflexo de uma compreensão extemporânea da própria saúde pública: como campo de conhecimento e de práticas, delimitado pelas estreitas divisas da epidemiologia, das doenças transmissíveis e da medicina preventiva. Ao contrário, tais marcos históricos, dentre outros, evidenciam a pertinência da análise bioética dos problemas relacionados com a saúde pública, no caso, a formulação de políticas e a gestão de serviços.

A conformação (trans) disciplinar e o reconhecimento social dado à bioética ocorreram em uma perspectiva que se aproxima bem mais da concepção holística proposta por Potter, ainda que nas análises aplicadas à clínica e à pesquisa o modelo principialista desenvolvido no Kennedy Institute of Ethics seja hegemônico. Pode ser conceituada como o estudo sistemático das dimensões morais das ciências da vida e dos cuidados da saúde, empregando uma variedade de metodologias. Como uma ética aplicada, possui duas dimensões indissociáveis, uma descritiva e uma normativa. Ou seja, preocupa-se em analisar os argumentos morais a favor e contra determinadas práticas humanas que afetam a qualidade de vida e o bem-estar dos humanos e dos outros seres vivos e a qualidade dos seus ambientes, e em tomar decisões baseadas nestas análises. Considerando-se de forma específica, mas não só, o campo da saúde pública, tem sido propugnado que a proteção seja o princípio norteador das análises e decisões a serem tomadas. Tal concepção é coerente com a Declaração Universal sobre Bioética e Direitos Humanos da UNESCO.

Tendo como referência o núcleo da saúde coletiva, “o apoio aos sistemas de saúde, à elaboração de políticas e à construção de modelos; a produção de explicações para os processos saúdelenfermidade/intervenção; $e$, (...), a produção de práticas de promoção [da saúde] e prevenção de doenças" (Ciênc Saúde Coletiva 2000; 5:219-30), é correto afirmar que a bioética, com suas teorias e métodos, não apenas tem contribuído como também deve continuar a contribuir para o desenvolvimento deste campo, com a análise e proposição de soluções para os problemas morais inerentes às suas práticas. Mas no Brasil e em boa parte da América Latina isso não deve se configurar como um problema, na medida em que a própria saúde coletiva se vê também como campo inter e transdisciplinar.

O desafio de considerar igualmente interesses individuais e coletivos, o bem individual e o coletivo é uma das tarefas da saúde pública com a qual a bioética pode contribuir de forma significativa. O desafio não é o de impor restrições às liberdades individuais, mas o de focar nos interesses da coletividade a formulação das políticas públicas, fundamentando-a criteriosamente do ponto de vista ético. Nossa história recente tem mostrado que o diálogo e a permanente busca de entendimento abrem caminho para a conformação de um sistema de saúde mais justo, assim como de suas práticas.

Sergio Rego

Escola Nacional de Saúde Pública Sergio Arouca, Fundação Oswaldo Cruz, Rio de Janeiro, Brasil.

rego@ensp.fiocruz.br 